\title{
Um olhar meticuloso das disciplinas experimentais dos cursos de física à distância
}

Maria Sônia Oliveira Veloso soniaufrr@gmail.com 0000-0002-2900-4967 Universidade Federal de RoraimaUFRR

Universidade Luterana do Brasil ULBRA

Agostinho Serrano asandraden@gmail.com 0000-0002-7868-1526

Universidade Luterana do Brasil ULBRA

\section{RESUMO}

Este trabalho tem o objetivo de verificar o que existe na prática de conteúdo sobre o ensino de Física experimental desenvolvida em laboratório, presencial e a distância, em cursos de licenciatura em Física a distância no Brasil. Utilizamos uma análise de conteúdo de onze currículos e de suas respectivas ementas, complementados com informações de dez coordenadores de curso. Criamos algumas categorias baseadas nos conteúdos experimentais estudados no curso. Além disso, identificamos a metodologia aplicada pelos professores nessas disciplinas experimentais. Com base nos resultados adquiridos, observamos que a maioria dos professores desenvolve suas disciplinas de forma semelhante às presenciais ministradas aos licenciandos, mas não descartando, quando possível, a utilização da plataforma virtual para complementar os encontros quando ocorrem no laboratório didático experimental no polo presencial. Conforme as diretrizes que encontramos, consideramos que os cursos tentam utilizar as exigências conforme as leis, com uma diversidade de metodologias, as quais apresentamos neste trabalho.

PALAVRAS-CHAVE: Física experimental. Educação à distância. Tecnologia. 


\section{INTRODUÇÃO}

A Educação a Distância (EaD) apresenta um contexto histórico com a evolução no passar do tempo. No ensino superior as experiências de EaD tiveram início nos anos de 1990, mas se consolidaram a partir do ano $2000 \mathrm{com}$ a Universidade Aberta do Brasil (UAB), que atualmente é gerenciada pela CAPES. Tal fato é atestado por suas bases legais estabelecidas pela Lei de Diretrizes e Bases da Educação Nacional - LDBEN (LEI n.o 9.394/96), cujo artigo 80 inseriu a modalidade de $\mathrm{EaD}$ no país, o que evidencia a importância dessa modalidade no contexto da educação nacional (MEC, 2010) e por sua inclusão nos Planos Nacionais de Educação (RODRIGUES et al., 2014). Sendo, portanto, uma estratégia de ampliação das possibilidades de democratização do acesso à educação.

Em destaque nos Projetos Políticos Curriculares (PPC) na maioria das Instituições Superiores de Ensino, a EaD tem sido apontada como uma ferramenta alternativa para enfrentar o desafio da formação docente. Essa meta é consubstanciada na Lei de Diretrizes e Bases da Educação Nacional - LDBEN (Lei 9394/96), que exige que todos os professores da Educação Básica tenham formação superior. Dessa forma, podemos verificar que, para garantir a consecução dessa meta, a EaD ganha relevância principalmente nesse momento em que se constitui como ação prioritária da política pública brasileira a ampliação dos programas de formação - inicial e continuada - dos professores. Seu objetivo é melhorar a qualidade da educação no país, sendo um dos argumentos principais apresentados nos documentos analisados dos cursos de licenciatura em Física a distância no Brasil.

Realizando uma comparação, Silva (2009) destaca que, nos países do Reino Unido, na Austrália, nos Estados Unidos, em países da Europa e na Nova Zelândia, a EaD foi estudada de forma a viabilizar a testagem e o questionamento da metodologia que estava sendo empregada no ensino superior em cursos a distância. Foram verificadas melhorias principalmente na utilização de experimentos em laboratórios didáticos para o ensino de Física.

Essa modalidade a distância, mediada pelas diferentes tecnologias digitais, permite a professores e licenciandos se envolverem em situações de ensino/aprendizagem, em espaços e tempos não compartilhados fisicamente, mas que atendam às suas necessidades e possibilidades, contribuindo assim para a garantia do direito à educação e ao exercício da cidadania. Nessa caminhada de garantias, temos o objetivo de verificar o que existe na prática de conteúdo sobre Física experimental desenvolvida em laboratório, presencial e a distância, em cursos de licenciatura em Física a distância no Brasil, com a oportunidade de responder a algumas perguntas que norteiam formadores da área de ensino, a saber: quais são as disciplinas experimentais trabalhadas no laboratório didático na EaD? Como são ministradas as disciplinas experimentais na EaD? Há o uso efetivo da tecnologia para a formação de professores de Física?

Nessa perspectiva de responder a essas três perguntas, obtivemos onze Projetos Pedagógicos Curriculares - $(\mathrm{PPC})^{1}$ que nos foram disponibilizados pelos coordenadores de cursos de licenciatura em física no país e tivemos a oportunidade de analisar dez currículos e ementas das Instituições Superiores de 
oportunidade surgiu quando obtivemos a colaboração dos coordenadores. Durante o processo, surgiram dúvidas em relação ao que se apresentava no PPC e no contexto das ementas de algumas disciplinas de Física experimental. Para tanto, destacamos as disciplinas e criamos categorias conforme o que observamos durante a análise. Ao questionarmos os coordenadores em relação às dúvidas que surgiram, obtivemos explicações que possibilitaram conhecer as características metodológicas desenvolvidas pelos professores que ministram essas disciplinas experimentais. Pontuamos essas explicações em forma de quadro com suas características metodológicas aplicadas pelos professores, destacando o uso de algumas tecnologias.

Nesse cenário, adotamos uma metodologia de análise bibliográfica descritiva com estudo de conteúdo. Realizamos um levantamento de documentos disponibilizados pelos coordenadores, bem como argumentos apresentados por eles, que responderam às dúvidas e perguntas levantadas durante a investigação. Portanto, este trabalho possibilita reunir conhecimentos em relação à forma que estão sendo ministradas as disciplinas de Física experimental. Além disso, apresentam-se os conteúdos que estão sendo pontuados nos currículos, estando ou não na conformidade de serem trabalhados com o uso do laboratório. Principalmente no que se refere à disponibilização do material com o uso do laboratório, sendo virtual ou real, e as gamas de possibilidades da utilização da tecnologia para a formação de futuros professores de Física que serão inseridos na Educação Básica.

Os resultados que obtivemos possibilitam um olhar no sentido de não somente conhecer os conteúdos estudados nas disciplinas de Física experimental, mas também a forma como são trabalhados, utilizando tecnologias que podem determinar caminhos para a aprendizagem e adicionalmente trazer outras possibilidades de conhecimento que nesse momento não foram exploradas neste trabalho.

Apresentamos a seguir alguns tópicos que fundamentam resumidamente o embasamento de uma revisão de leis e pesquisas; em seguida, a metodologia com a análise dos dados e discussão, que foram utilizadas para expressar as respostas que obtivemos. E para finalização, pontuamos as considerações com propostas que poderão determinar outros estudos, bem como as referências que complementam este trabalho.

\section{EMBASAMENTO DE REVISÃO DE LEIS E PESQUISAS}

Realizamos uma verificação do que as leis determinam para formação de professores para a área de Ciências, ou, especificamente, para a Física. Esses aspectos podem nos orientar sobre as bases de habilidades e competências que os futuros professores devem desenvolver durante sua formação. Assim, ao estudar e analisar a LDB e as Diretrizes Curriculares para a formação de professores, destacamos que: deve ser um profissional apoiado em conhecimentos sólidos e atualizados em Física; deve ser capaz de abordar e tratar problemas novos e tradicionais, e deve estar sempre preocupado em buscar novas formas do saber e do fazer científico ou tecnológico (BRASIL, 2001). "Físico-educador", é importante que se dedique preferencialmente à formação e 
à disseminação do saber científico em diferentes instâncias sociais, seja por intermédio da atuação no ensino escolar formal, seja por meio de novas formas de educação científica, tais como vídeos, softwares, ou outros meios de comunicação; não se atendo ao perfil da atual licenciatura em Física, que está orientada para o ensino médio formal (BRASIL, 2001). Com a dominância da comunicação, podemos destacar que a modalidade de EaD vem complementar essa comunicação com suas possibilidades de ferramentas, como fórum, chats etc.

Fazendo uma comparação do que foi analisado nos PPC e verificando as bases nas diretrizes curriculares que afirmam a autonomia das IFES, elas determinam quais as competências e habilidades que podem ser trabalhadas para a formação dos professores de Física. Dessa forma, verificamos que essas bases de autonomia são dadas da seguinte forma:

\begin{abstract}
Às habilidades e competências específicas, estas devem ser elaboradas pelas IES a fim de atenderem às exigências dos mercados nacionais e locais. Nesse sentido, as diretrizes curriculares conferem toda autonomia às IES para defini-las, através dos conteúdos curriculares. Estes podem ser estruturados modularmente de modo a atenderem aos perfis gerais que são destacados, porém com mudanças nos módulos dos últimos quatro semestres do curso, que atenderiam ao tipo de especialização necessária para a inserção do formando na atividade almejada (BRASIL, 2001).
\end{abstract}

Para completar esta etapa de entendimento da estrutura curricular dos cursos que foram analisados, buscamos verificar o que é orientado pelas diretrizes curriculares em relação aos conteúdos que devem ser estudados no curso de Física. Percebemos, dessa forma, que há várias orientações. Em vista disso, tentamos destacar uma definição resumida. Assim, ela diz que se devem ter divididas, no PPC, duas estruturas; sendo uma o núcleo comum, que abrange todas as modalidades do curso de Física, com os conteúdos gerais para a formação, e outra, os módulos sequenciais especializados, nos quais será dada a orientação final do curso para os licenciandos.

No referencial de qualidade para a $\mathrm{EaD}$ é destacado que o curso deve apresentar claramente sua opção epistemológica de educação, de currículo, de ensino, de aprendizagem, de perfil do estudante que deseja formar; com definição, delineando princípios e diretrizes que alicerçarão o desenvolvimento do processo de ensino e aprendizagem (BRASIL, 2007). Baseado nesse pressuposto de analisar os currículos e as ementas dos cursos de Física a distância do Brasil, visando analisar exatamente as disciplinas que têm como foco a atividade experimental, observamos esse cuidado epistemológico de deixar claro no currículo esses princípios.

Tendo esse determinante de qualidade para a formação de futuros professores de Física que serão inseridos para trabalharem com ensino básico, trazemos como complemento para este estudo a visão de Netto e Girafa (2009), os quais apontam que, nos últimos anos, a busca pela qualidade passou a ser um dos objetivos da Universidade Nacional de Educação a Distância (UNED) no Espaço Europeu de Educação Superior. Nesse sentido, foi criada a Oficina de Planificação e Qualidade, com o objetivo de elaborar e revisar os indicadores internos de qualidade da universidade, para que a oferta de cursos propicie a máxima satisfação dos grupos de interesse. 
Podemos destacar também a Open University, na Inglaterra, que possui índices excelentes de qualidade nos seguintes indicadores de cursos a distância: projeto pedagógico, professores capacitados, proporção adequada licenciandos/professor, material didático e avaliação (LLOYD, 2008). Além disso, a Open University possui um sistema de acesso aberto, ou seja, os licenciandos não precisam passar por provas de vestibular para ingressarem em muitos dos cursos de graduação oferecidos. Apesar de não possuir um processo seletivo, a universidade tem credibilidade dos licenciandos, do governo e da sociedade. Isso se deve aos índices excelentes de qualidade que a colocaram em primeiro lugar entre as Instituições de Ensino Superior na Inglaterra, País de Gales e na Irlanda do Norte, na Pesquisa Nacional de Alunos (LLOYD, 2008).

Esse ponto de indicadores para qualidade do ensino, que Netto e Girafa (2009) apresentam, possibilitou-nos uma visão codificada com a análise dos currículos e ementas, associando a utilização de um ambiente virtual que se caracteriza como um laboratório e/ou laboratório didático presencial, que também é pontuado por eles, sendo parte da categoria de infraestrutura.

Netto e Girafa (2010) destacam a vantagem de se utilizar o laboratório virtual, possibilitando aos licenciandos o acesso aos recursos de experimentação sem restrições de tempo e de espaço que oferecem os laboratórios reais.

Com a utilização do laboratório virtual é preciso que haja objetos de aprendizado que sejam estimulantes, tais como animações, simulações, atividades com as quais os licenciandos possam interagir. Formas que façam o licenciando entender a concretização daquele conhecimento, sendo essencial a criação de espaço em que os estudantes descubram a sua habilidade e desenvolvam outras, como bem observam Netto e Girafa (2010).

Ao encontro desta pesquisa, foi analisado em outros momentos como ocorre a interação entre o conhecimento de aulas teóricas e o conhecimento de aulas experimentais no ensino de física a distância no ambiente virtual, registrado por Veloso e Andrade (2016).

Na ideia de comparações em relação a outros ambientes virtuais que possibilitam trabalhar com simulações e atividades virtuais, verificamos também, o trabalho de Guterres et al. (2018), os quais analisaram três plataformas que são utilizadas para momentos das atividades experimentais. As principais plataformas didáticas que são utilizadas por instituições de ensino superior, a saber, Phet, Modellus e LabVirt, caracterizando suas metodologias diversificadas com interfaces diferenciadas.

Guterres et al. (2018) consideram que, no caso dessas três plataformas, uma complementa a outra. O Phet possui o laboratório virtual já pronto com todas as ferramentas; o Modellus permite a construção do laboratório virtual; e o Labvirt (Física) possui a parte didática por meio de histórias e situações problemas.

Diante dessa comparação que fizeram dessas três plataformas, observaram que há ainda a necessidade de plataformas didáticas que abordem os assuntos que abrangem calor e termodinâmica, eletricidade, magnetismo e até mesmo a Física moderna. Esses assuntos são poucos explorados nas plataformas que foram estudadas (GUTERRES et al., 2018). Naturalmente estes tópicos são de grande interesse geral, mas fora do escopo deste artigo. 


\section{METODOLOGIA DO TRABALHO}

A pesquisa constituiu-se em uma análise de conteúdo, contando, para tal, com levantamento bibliográfico, com apoio nos testemunhos dos coordenadores de cursos de licenciatura em Física na modalidade a distância. Com embasamento das ideias de Cavalcante et al. (2014), determinamos as perguntas com o propósito de responder, conforme o surgimento da descrição, que a análise de conteúdo nos propositou, utilizando algumas das ideias de Bardin (2011).

Adotamos operacionalmente as etapas de uma pré-análise a partir da leitura dos onze PPC das instituições privadas e públicas distribuídas nas regiões do Brasil. Realizamos uma exploração do material, determinando uma codificação do corpus, criando dessa forma as categorias baseadas nos conteúdos trabalhados nas Físicas experimentais. Em seguida realizamos o tratamento dos resultados obtidos, associados com os testemunhos dos coordenadores de curso, apresentados por e-mail, os quais responderam às perguntas em foco neste trabalho, seguido da interpretação dos resultados.

\subsection{ANÁLISE DOS DADOS}

Com o critério de conhecer as disciplinas que são ministradas, foi necessário estudar cada PPC e verificar quais eram as disciplinas trabalhadas no laboratório didático. Entretanto, foi imprescindível criar categorias que pudessem abranger as disciplinas que estavam sendo mencionadas no PPC de cada instituição, para que não fosse necessário colocar todas elas no Quadro 1. Outro ponto a considerar para a preservação desse quadro é que a mesma traz as instituições representadas por códigos e as regiões.

Conforme a criação das categorias baseadas nas análises dos currículos e das ementas, codificamos as falas dos coordenadores diante das perguntas que foram apresentadas para eles via e-mail. Foram enviadas para onze coordenadores duas perguntas cujas respostas são apresentadas nos Quadro 2A a 2J. Nessa dinâmica de contato, obtivemos o retorno de dez coordenadores.

Os Quadros 2A a $2 \mathrm{~J}$ apresenta as respostas que obtivemos dos coordenadores em relação às disciplinas, à metodologia aplicada e à caracterização do local onde são desenvolvidas essas disciplinas experimentais.

Uma observação importante é a respeito da nomenclatura utilizado por alguns entrevistados. As disciplinas intituladas de física básica, de maneira geral, expõem experimentos de física com tratamento conceitual e matemático compatível com o ensino médio e são em geral oferecidas logo no início do curso. As disciplinas de Física I, II, III e IV referem-se à denominação usual de livrostextos clássicos, e correspondem aos conteúdos introdutórios (em nível superior) de mecânica; calor, ondas e gravitação; eletromagnetismo e finalmente óptica e física moderna.

\section{DISCUSSÃO DOS DADOS}




\begin{tabular}{|c|c|c|}
\hline Categorias & Instituição & Região \\
\hline Introdução à Física & $\mathrm{A} 1$ & Norte, Sul, Sudeste, Nordeste \\
\hline \multirow{3}{*}{ Erros e Medidas Físicas } & $\mathrm{A} 1$ & Norte, Sul, Sudeste, Nordeste \\
\hline & $\mathrm{B} 2, \mathrm{C} 3$ e $\mathrm{D} 4$ & Nordeste \\
\hline & E5 e F6 & Sudeste \\
\hline \multirow{4}{*}{ Cinemática } & $\mathrm{A} 1$ & Norte, Sul, Sudeste, Nordeste \\
\hline & F6, B2, G7 & Sudeste \\
\hline & E5, H8 & Sudeste \\
\hline & $\mathrm{D} 4,19$ & Nordeste \\
\hline \multirow{4}{*}{ Dinâmica } & F6 & Sudeste \\
\hline & J10 & Sul, Sudeste \\
\hline & B2, C3, L11, M12, D4, I9 & Nordeste \\
\hline & A1 & Norte, Sul, Sudeste, Nordeste \\
\hline \multirow{4}{*}{$\begin{array}{l}\text { Energia e Momento } \\
\text { Linear }\end{array}$} & $\mathrm{J} 10$ & Sul, Sudeste \\
\hline & A1 & Norte, Sul, Sudeste, Nordeste \\
\hline & $\mathrm{D} 4,19$ & Nordeste \\
\hline & H8, F6, E5 & Sudeste \\
\hline \multirow{5}{*}{ Termodinâmica } & $\mathrm{A} 1$ & Norte, Sul, Sudeste, Nordeste \\
\hline & L11, B2, C3, M12, I9 & Nordeste \\
\hline & $\mathrm{H} 8, \mathrm{F6}$ & Sudeste \\
\hline & $\mathrm{J} 10$ & Sul, Sudeste \\
\hline & Instituição & Região \\
\hline \multirow{4}{*}{ Fluidos } & E5, F6 & Sudeste \\
\hline & $\mathrm{J} 10$ & Sul, Sudeste \\
\hline & $\mathrm{B} 2,19, \mathrm{C} 3, \mathrm{M} 12$ & Nordeste \\
\hline & A1 & Norte, Sul, Sudeste, Nordeste \\
\hline \multirow{3}{*}{ Eletricidade } & 19, L11, B2, C3, M12 & Nordeste \\
\hline & J10 & Sul, Sudeste \\
\hline & F6, E5, H8 & Sudeste \\
\hline \multirow{3}{*}{ Magnetismo } & E5, H8, F6 & Sudeste \\
\hline & M12, I9, L11, B12, C3, D4 & Nordeste \\
\hline & $\mathrm{J} 10$ & Sul, Sudeste \\
\hline \multirow{3}{*}{$\begin{array}{l}\text { Quântica Antiga (Semi- } \\
\text { Quântica) }\end{array}$} & $\mathrm{J} 10$ & Sul, Sudeste \\
\hline & M12, 19, D4 & Nordeste \\
\hline & $\mathrm{H} 8$ & Sudeste \\
\hline \multirow{2}{*}{ Quântica } & $\mathrm{J} 10$ & Sul, Sudeste \\
\hline & 19, C3, L11 & Nordeste \\
\hline \multirow{3}{*}{ Óptica } & $\mathrm{F} 6, \mathrm{E} 5, \mathrm{H} 8$ & Sudeste \\
\hline & $\mathrm{J} 10$ & Sul, Sudeste \\
\hline & $\mathrm{B} 12, \mathrm{C} 3, \mathrm{M} 12, \mathrm{I9}, \mathrm{D} 4$ & Nordeste \\
\hline \multirow{3}{*}{ Oscilações e Ondas } & $\mathrm{A} 1$ & Norte, Sul, Sudeste, Nordeste \\
\hline & $\mathrm{B} 12, \mathrm{C} 3, \mathrm{D} 4,19, \mathrm{~L} 11$ & Nordeste \\
\hline & F6, E5 & Sudeste \\
\hline
\end{tabular}

(Fonte - Dos PPC dos cursos de Física a distância do Brasil)

Trazendo alguns pontos essenciais para a discussão do Quadro 1, apresentamos a seguir uma análise baseada nos documentos que foram disponibilizados para este estudo. O Quadro 1 é um resumo do que conseguimos extrair para responder aos questionamentos. Conforme as categorias que adotamos, baseadas nas disciplinas e nos conteúdos apresentados nos PPC. Diante do que está sendo questionado neste trabalho, são apresentadas estas 
categorias, as quais são distribuídas de forma sequencial no princípio do curso de Física.

Nessa perspectiva, podemos observar que a Física Básica, que é considerada com essa nomenclatura, aborda os princípios de erros e medidas, entretanto, não sendo trabalhada por todas as instituições, conforme verificamos. No apontamento dos currículos, evidencia-se quais são as disciplinas trabalhadas em forma de atividade experimental. Em vista disso, percebe-se que, das onze instituições, somente seis demonstram utilizar a nomenclatura de Erros e Medidas Físicas.

Para as categorias Cinemática e Dinâmica, que abrangem conhecimentos sobre o estudo dos movimentos e das leis de Newton, podemos evidenciar na leitura dos currículos, que varia de oito instituições que registram trabalhar a Cinemática e nove instituições que trabalham a Dinâmica. Nessas duas categorias, observa-se que ocorre o princípio do curso de Física, envolvendo conhecimentos que possibilitam ao licenciando sedimentar o que ele estudou na teoria ao iniciar o curso.

Para as categorias Energia e Momento Linear, e Termodinâmica, evidencia-se no quadro que sete instituições abordam Energia e Momento Linear, e dez instituições abordam a Termodinâmica. Para algumas dessas categorias, ficam evidentes os procedimentos e as determinações de fórmulas e dotação da matemática.

Para as categorias Fluidos e Eletricidade, variam entre oito instituições para Fluidos, e nove instituições evidenciam em seus currículos que trabalham Eletricidade. Principalmente, pela adoção de equipamentos, que muitas vezes são kits já prontos, disponibilizados para o licenciando. Nessa determinação de metodologia, há a possibilidade de o aluno ser guiado por um roteiro, ou equipamentos disponibilizados nos laboratórios com a aparelhagem necessária para a execução do experimento.

Para as categorias Magnetismo e Quântica Antiga (Semi-Quântica), estão registradas dez instituições que trabalham essas categorias. Sendo que cinco instituições abordam esse assunto no seu curso em forma de atividade experimental. Nessas categorias, começamos a querer saber como seria a metodologia adotada para trabalhar esses assuntos e se os licenciandos teriam desenvolvimento de atividades presenciais ou virtuais, pois os procedimentos não estavam claros nos currículos, sendo que uma ou outra instituição afirma que essa questão fica a critério do professor da disciplina.

Nas categorias Quântica, Óptica e Oscilações e Ondas, fica clara no quadro uma variação, igual às demais instituições que trabalham esses assuntos. Para a Quântica, que diferenciamos da Quântica Antiga, quatro instituições evidenciam em seu currículo o seu estudo; já para a Óptica, constatamos nove instituições, e para Oscilações e Ondas, oito instituições.

Em termos gerais, baseados em todos os documentos analisados para a construção do Quadro 1 e a formação para discussão dos dados, evidenciamos que as disciplinas pedagógicas e laboratoriais desses cursos de Física têm a pretensão de preverem competências referentes ao processo de investigação que possibilitem o aperfeiçoamento da prática pedagógica. 
Observamos que as disciplinas foram elaboradas de tal maneira que exista sempre uma atividade experimental e uma discussão com fundo didáticopedagógico relacionada às atividades teórico-expositivas. Entretanto, fica evidente em quase todos os documentos analisados que as instituições seguem uma forma de apresentação, segundo a visão de que todas as etapas do curso possam ser executadas detalhadamente.

Com o uso da tecnologia, verifica-se que, das onze instituições, duas fazem uso de uma plataforma própria. Seguindo essa determinação, elas se dedicam a planejar a construção de tecnologia própria, buscando alcançar condições de excelência nos serviços oferecidos, o que é justificado pelas instituições em seus PPC. As outras instituições utilizam a plataforma Moodle, com seus designs diversificados, com a utilização de uma variedade de ferramentas que a plataforma possibilita explorar.

Não trouxemos para o Quadro 1 os detalhes da metodologia utilizada e o local onde são executadas essas atividades experimentais, porque o nosso intuito era o de questionar e obter a participação dos coordenadores para este levantamento que realizamos naquele quadro. De igual forma, não pontuamos a infraestrutura por completa, nem a equipe envolvida, não que isso não fosse possível de se observar nos documentos; até foi observado, mas o nosso direcionamento foi somente extrair as disciplinas experimentais e as formas com que são trabalhadas as várias oportunidades de se utilizar a tecnologia.

Como já mencionado anteriormente, o nosso olhar clínico centrou-se nas disciplinas experimentais. Determinamos, nesse sentido, pontuá-las de forma a que pudéssemos apresentar os conhecimentos que os licenciandos estão tendo da Física. Com essa oportunidade, produzimos, em forma de duas perguntas, o que pudesse esclarecer as dúvidas que surgiram durante o processo de análise dos currículos. Dessa forma, adotamos alguns procedimentos que esclareceram a configuração da metodologia utilizada e como são definidos e explorados os laboratórios didáticos, sendo eles virtual ou/e real.

$\mathrm{Na}$ visão de complementar o Quadro 1, trouxemos a participação dos coordenadores diante das dúvidas que surgiram. Entretanto, queríamos ter a certeza do que estava escrito nos currículos e nas ementas apresentadas nos PPC dos cursos de Física, ou seja, se são realmente executadas na prática. A dinâmica se deu da seguinte forma: levantar as dúvidas dentro de duas perguntas e enviar para os coordenadores via e-mail. Então, assim foi o procedimento, sendo enviadas para os onze coordenadores de curso. As perguntas enviadas foram:

\section{Quais as metodologias utilizadas nas disciplinas experimentais?}

2. Como é caracterizado o laboratório didático para cada disciplina trabalhada? Laboratório presencial (polo), a distância (plataforma Moodle) ou semipresencial (polo e plataforma Moodle)?

Com o retorno dos coordenadores com as respostas, na originalização dos textos, tentamos preservar na íntegra o que cada um respondeu. Com as perguntas que surgiram ao analisar os currículos e tendo o retorno dos coordenadores, definimos nos Quadros $2 \mathrm{~A}$ a $2 \mathrm{~J}$, com características essenciais que evidenciaram os procedimentos metodológicos, didáticos e tecnológicos trabalhados nos cursos dessas dez instituições que nos responderam. Fazendo uma análise por instituição e respostas, observamos os seguintes apontamentos: 
Os laboratórios introdutórios de ICFI e ICFII (introdução à física) seguem uma apostila do CEDERJ, onde são discutidas algumas experiências de óptica, termodinâmica e eletricidade. As experiências são muito simples e estão disponíveis nos polos de apoio. 0 laboratório de ICFI discute somente fenômenos ópticos e é baseado em um kit que foi desenvolvido pelo CEDERJ. A ideia aqui não é estudar óptica, mas sim metodologias de medidas experimentais. No laboratório de ICFII usamos procedimentos equivalentes só que com experimentos de termodinâmica e eletricidade. Nesse caso, utilizamos materiais adquiridos da CIDEPE.

Com relação aos laboratórios avançados de Física I, II, III e IV (esta denominação segue o padrão usual dos livros-texto mais comuns do mercado), não temos por enquanto disponibilidade de materiais e equipamentos nos polos de apoio. Estamos utilizando uma metodologia semipresencial, em que são usados videoaulas e simulações na plataforma Moodle e, atualmente, agendamento de uma única visita aos laboratórios da JF. A visita é feita durante um final de semana, e os licenciandos fazem de 5 a 6 experiências que foram largamente discutidas na plataforma Moodle. As práticas são cuidadosamente escolhidas de uma série de experiências que são realizadas na JF com o ensino presencial. Para cada experimento, o aluno, ou grupo de licenciandos, deve apresentar posteriormente um relatório de execução. Esse procedimento não é o ideal, mas tem funcionado satisfatoriamente.

(Fonte - Organizado pelos autores)

Nesta instituição, há utilização de um material didático que não é montado pela própria instituição, sendo que essas informações não foram identificadas no PPC do curso. Parece que há uma parceria de uma outra instituição na construção do livro didático, porém não sendo para todas as disciplinas experimentais, somente para as introdutórias experimentais. As Físicas experimentais I, II, III e IV não têm materiais e nem equipamentos nos polos de apoio. Para que os licenciandos não fiquem sem o acesso ao manuseio de equipamentos, é utilizada a estrutura da instituição para o acesso aos laboratórios didáticos reais. Para o complemento da atividade realizada no laboratório da instituição, utilizam também uma metodologia semipresencial, pela qual são realizadas simulações e videoaulas, apresentadas na plataforma Moodle. De modo que a plataforma fica sendo utilizada para o complemento das atividades experimentais executadas presencialmente na instituição. No PPC, transparece que há equipamentos e que a plataforma é explorada a partir de várias possibilidades para o desenvolvimento das disciplinas.

\section{Quadro 2B - Resposta do coordenador da instituição H8}

Venho seguindo o plano de ensino da disciplina, com webconferências, realização com pequenos vídeos com orientações para realização dos experimentos e o roteiro de cada experimento (tudo disponível na plataforma).

Os polos possuem laboratório com experimentos somente de Mecânica e Termodinâmica, que equivalem aos conteúdos de Física Experimental I e II. Nessas duas disciplinas, eu elaborei o roteiro de realização dos experimentos (três) e gravei pequenos vídeos com orientações para sua execução. Usei uma web para discutir os resultados de cada experimento. Na disciplina de Física Experimental III, eu elaborei três experimentos e visitei todos os polos para que os licenciandos pudessem executar os experimentos. Ainda estou planejando a disciplina de Física Experimental IV, que será ofertada em 2016/2. Em todas as disciplinas, eu também lancei um objetivo e pedi que elaborassem um roteiro para atingir tal objetivo e em seguida o executassem. 
$\mathrm{Na} \mathrm{H} 8$, são seguidas as etapas do plano de curso, disponibilizando para o licenciando várias possibilidades de aproximação: uso de webconferência, agendada com antecedência, assim como vídeos gravados pelo professor da disciplina experimental demonstrando a execução da atividade em laboratório com a explicação dos procedimentos dos roteiros disponibilizados na plataforma. No PPC, não se esclarecem as formas metodológicas. Desse modo, o que se destaca sobre a metodologia adotada é que se utiliza uma metodologia mista: presencial itinerante e a distância.

A explicação apresentada evidenciou que não há equipamentos disponíveis nos polos para serem trabalhadas as Físicas experimentais III e IV, tendo somente experimentos de Mecânica e Termodinâmica. Com a flexibilidade para o desenvolvimento de metodologias apropriadas para serem trabalhadas as disciplinas experimentais, é esclarecido que foram utilizadas algumas formas metodológicas, tais como roteiro, gravação de vídeos com orientações, uso da web para discutir os resultados e determinação de objetivos para execução das atividades experimentais. Todos os procedimentos são executados, na maioria das vezes, nos polos e, quando necessário, é utilizada a plataforma para disponibilização de algum vídeo e/ou orientação para a realização das atividades e postagem dos relatórios pelo fórum. Não fica evidenciado no PPC, contudo, o uso de simulação ou outra forma de atividade virtual, assim como também não é mencionado nas respostas apresentadas.

Quadro 2C - Resposta do coordenador da instituição 19

As disciplinas com horas práticas dedicam essas horas às aulas nos laboratórios físicos que se encontram nos polos no interior do RN. No entanto, alguns professores utilizam simuladores que fazem a vez desses laboratórios, visto que nem todo experimento encontra-se disponível nos laboratórios dos polos. Todas as disciplinas que estão no PPC fazem uso desse tipo de ferramenta, o que auxilia a aprendizagem dos licenciandos de nosso curso.

(Fonte - Organizado pelos autores)

Evidenciamos nesse curso um PPC bem sucinto, sem muitas voltas para detalhamento do que realmente ocorre no curso. Percebe-se que fica flexível o uso dos simuladores nos procedimentos das atividades experimentais, sendo explicado também que nem todo experimento é encontrado disponível nos laboratórios nos polos. Todas as horas práticas são utilizadas das estruturas de laboratório didático físico. Na consulta do PPC, fica evidenciado que no "Laboratório de Ensino", assim mencionado, podem ser montadas cerca de 50 experiências didáticas básicas. Várias dessas experiências, a exemplo do Laboratório de Cores, serviram de base para pequenos cursos em eventos nacionais, sendo esse esclarecimento retirado dos trechos do PPC do curso. Também, destaca-se no PPC que há disponibilização de kits de laboratório de Física com experimentos em Física clássica e Física moderna, disponibilizados nos polos para serem manuseados pelos licenciandos acompanhados do tutor; kits de Física com experimentos virtuais desenvolvidos por uma equipe e/ou adquiridos no mercado especializado. Relacionado ao suporte tecnológico, há sistemas multimeios (CD-ROM), videoconferência etc., com computadores instalados nos polos na quantidade necessária com facilidades de software e acesso à internet. Todavia, isso não foi confirmado com as respostas adquiridas com o coordenador. 

serem realizados. Por isso, pode-se saber as disciplinas em que a parte experimental foi integrada à teoria. Por outro lado, não consta no projeto o tempo dos experimentos. Isso fica a critério do professor da disciplina.

As instituições de ensino superior têm laboratórios didáticos. Em particular, os Departamentos de Física têm laboratórios didáticos para as disciplinas de caráter prático. Quando um professor de alguma disciplina do nosso curso de EaD resolve realizar um experimento, ele usa o material disponibilizado pelo departamento, deslocando-se ao polo de interesse. Então, como todo professor de disciplinas de laboratório, ele desenvolve a atividade conforme sua vontade e planejamento.

(Fonte - Organizado pelos autores)

Para esta instituição, obtivemos como resposta bem direcionada para verificar no PPC do curso. Mas, ao disponibilizar o documento, foram páginas resumidas em partes, como se não tivesse fazendo a conexão de um documento por completo. De modo que, embora tenham dito que no PPC está claro, ao analisar essas páginas das partes do documento que definem como funciona um curso, não se transpareceu essa clareza. Ao realizar uma leitura flutuante das páginas que foram disponibilizadas, vai ao encontro daquilo que nos é apresentado nas entrelinhas, quando se coloca que no PPC não consta o tempo das disciplinas, tampouco o tempo dos experimentos.

Fica evidenciado, portanto, que o professor tem uma flexibilidade em definir o tempo da realização das atividades dos experimentos. Outro ponto que não ficou claro no PPC, mas obtivemos como resposta quando questionamos, foi sobre o laboratório. Percebe-se que se utilizam laboratórios didáticos reais disponibilizados pelo departamento do curso de Física presencial. Outro ponto que nos chamou a atenção é quando se afirma que, se um professor resolve realizar um experimento, ele usa o material disponibilizado pelo departamento, deslocando-se ao polo de interesse. Enfim, parece que não há uma separação de disciplinas experimentais, pois não visualizamos isso claramente no PPC. Com essa afirmação, fica evidenciado que a experimentação ocorre vinculada às aulas teóricas quando estão sendo ministradas. Em relação ao uso da plataforma e aos outros meios de tecnologia, não há clareza no PPC e nem nas afirmações pontuadas como resposta.

Quadro 2E - Resposta do coordenador da instituição C3

As disciplinas experimentais são todas presenciais. Em geral são feitos de um a dois encontros presenciais para a realização dos experimentos. A parte de relatório eles fazem a distância. Não usamos softwares ou outros recursos, apenas os experimentos do laboratório presencial. Eles realizam o experimento e fazem um relatório interpretando os dados obtidos. Temos kits experimentais para todos os conteúdos que são ministrados. Não temos um experimento especificamente sobre gravitação. Às vezes um ou outro professor possa adotar uma metodologia um pouco diferente da que relatei acima. Mas, esse é em geral o procedimento padrão seguido por todos.

(Fonte - Organizado pelos autores)

Esse curso se utiliza dos momentos presenciais para realizar as disciplinas experimentais, ficando somente com característica a distância o desenvolvimento do relatório e da entrega pela plataforma Moodle. Não utilizam softwares ou outros recursos; apenas os experimentos do laboratório presencial, sendo que 
este é plenamente agendado pelo professor responsável pela disciplina, podendo ser um ou dois encontros no polo, obtendo de diversos kits experimentais os conteúdos que são ministrados. O professor pode até adotar outras formas de metodologias, mas os procedimentos podem não variar muito, conforme o que foi verificado no PPC do curso.

Tudo que foi relatado se confirma no PPC; porém, quando se coloca que a gravitação não tem um experimento específico, o mesmo foi levantado como questionamento ao analisar o PPC, visto que é estudado com outros assuntos quando apresentado ao licenciando. Percebe-se que não há o uso de atividades virtuais, somente de atividades práticas que podem ser manuseadas no laboratório do polo.

\section{(Quadro 2F - Resposta do coordenador da instituição B12)}

Em cada disciplina constam 8 aulas práticas. As práticas são realizadas duas a duas em quatro encontros presenciais. Além desses quatro encontros presenciais temos mais um encontro presencial para revisão e um para avaliação.

As práticas são realizadas com material desenvolvido por mim aqui na FC. Poucas práticas são baseadas em equipamentos existentes nos polos.

Acontece que nem todo polo tem laboratório e os que o possuem, nem sempre podemos contar que os equipamentos estejam em condições de uso.

\section{(Fonte - Organizado pelos autores)}

Para as disciplinas experimentais da instituição B12, observou-se que ocorrem oito aulas práticas, com uma divisão de encontros para o melhor aproveitamento das atividades. Todos os encontros para a realização das atividades experimentais são executados presencialmente, acompanhados de revisão e avaliação. O material é desenvolvido pelo professor responsável pela disciplina experimental, pois poucas práticas são baseadas em equipamentos existentes no polo.

Percebe-se mais uma evidência de que o polo não tem todos os equipamentos necessários para execução das atividades, tendo o professor que se utilizar de metodologias com material que possibilite desenvolvimento de habilidades necessárias para a aprendizagem. Dessa forma, percebe-se que nem todos os polos têm laboratório e quando têm não é garantida a utilização dos equipamentos. Pontos esses não evidenciados no PPC. Destaque-se a flexibilidade do professor ao trabalhar as disciplinas experimentais, a saber, desde a Física experimental I até a Física experimental IV. Com essa possibilidade de variar com a metodologia, percebe-se que há uma visão para o incentivo de utilizar tecnologias que possam completar as atividades experimentais no polo, como uma simulação por exemplo. Um outro ponto que levantamos, para comparação com a utilização de tecnologia diferenciada, está relacionado à plataforma em que o licenciando está inserido. No PPC é evidenciado que a instituição tem uma plataforma própria para o funcionamento do curso, diferenciada do Moodle.

\section{Quadro 2G - Resposta do coordenador da instituição A1}

Os laboratórios introdutórios seguem uma apostila da universidade, onde são discutidas algumas experiências de óptica, termodinâmica e eletricidade. As experiências são muito simples e estão disponíveis nos polos de apoio. 0 laboratório de primeira disciplina de física experimental discute somente 
fenômenos ópticos e é baseado em um kit que foi desenvolvido pela universidade. A ideia aqui não é estudar óptica, mas sim metodologias de medidas experimentais. No laboratório de da segunda disciplina de física experimental usamos procedimentos equivalentes só que com experimentos de termodinâmica e eletricidade. Nesse caso, utilizamos materiais adquiridos de um fornecedor de experimentos didáticos privado.

Com relação aos laboratórios avançados de Física I, II, III e IV, não temos por enquanto disponibilidade de materiais e equipamentos nos polos de apoio. Estamos utilizando uma metodologia semipresencial, onde são usados vídeo aulas e simulações na plataforma Moodle e, atualmente, agendamento de uma única visita aos laboratórios presenciais da universidade. A visita é feita durante um final de semana, e os alunos fazem de 5 a 6 experiências que foram largamente discutidas na plataforma Moodle. As práticas são cuidadosamente escolhidas de uma série de experiências que são realizadas na universidade com o ensino presencial. Para cada experimento, o aluno, ou grupo de alunos, deve apresentar posteriormente um relatório de execução. Esse procedimento não é o ideal mas tem funcionado satisfatoriamente.

(Fonte - Organizado pelos autores)

Com esta instituição, dois pontos apresentados no PPC nos chamaram a atenção. Primeiro em relação à metodologia utilizada, sendo totalmente a distância o desenvolvimento das disciplinas experimentais. O licenciando recebe em sua casa os kits de laboratório, contendo material para realizar atividades experimentais envolvendo Física Básica com conhecimentos sobre Erros e Medidas, Física experimental I, Física experimental II. A instituição contrata a empresa para montar os kits e enviar para os licenciandos que estão cursando as disciplinas experimentais, com isso os licenciandos utilizam o roteiro que acompanha o kit, realiza as atividades propostas no ambiente virtual e quando está com dúvidas, procura o tutor no polo.

Com as respostas que obtivemos, esclarece-se esse ponto sobre a forma metodológica que é desenvolvida nessas disciplinas experimentais. Entretanto, isso não fica claro em relação a outras disciplinas que estão pontuadas no PPC, como realização de atividades em laboratório, por exemplo. Aparece para ser realizado, mas ao comparar com a resposta que recebemos, elas não são mencionadas. Todo o contato é feito pela plataforma do curso, desde orientação e auxílio em dúvidas, até realização de entrega de atividades.

$\mathrm{O}$ segundo ponto que nos chamou a atenção está relacionado à plataforma. Esta instituição apresenta no seu PPC que utiliza uma plataforma própria para a execução do curso, sendo diferenciada do Moodle.

\section{Quadro 2H - Resposta do coordenador da instituição E5}

As disciplinas experimentais (mecânica, termodinâmica, eletricidade, magnetismo etc.), na modalidade a distância, são atividades presenciais, realizadas nos polos de apoio presencial em que o professor leva um kit da universidade, que pode ser um material alternativo ou mais elaborado e realiza as atividades, organizadas num roteiro, junto com os licenciandos e apoiado por um tutor. A metodologia consiste numa explicação da atividade, utilizando o quadro, projeção e um roteiro. Dependendo do tamanho da turma as atividades são realizadas em duplas ou mais 
num momento posterior deverão entregar um relatório da(s) atividade(s) experimental(is).

São realizadas no polo de apoio presencial, porém os professores utilizam experimentos reais em forma de kit, ou uma vídeo-gravação de um experimento. Os docentes têm liberdade de utilizar simulações para exemplificar um fenômeno, mas as atividades experimentais são basicamente em forma de montagem de um experimento (com materiais alternativos ou kits já prontos) seguido de um roteiro para a elaboração do relatório. Outra maneira de desenvolver as atividades experimentais consiste na gravação do experimento (mecânica, termodinâmica, eletricidade, magnetismo etc.) nos laboratórios da universidade em que é disponibilizado aos licenciandos no Moodle, juntamente com um roteiro em que os licenciandos no polo de apoio presencial, junto com o tutor presencial, deverão também obter os dados e preencher um roteiro. Num momento posterior, os licenciandos deverão entregar um relatório da(s) atividade(s) experimental(is) através do Moodle.

(Fonte - Organizado pelos autores)

Esta instituição tentou apresentar, bem pontualmente, como é feita metodologicamente a execução das disciplinas experimentais. Deixou esclarecido que as disciplinas são realizadas presencialmente, podendo até ter uma variação para momentos a distância com a utilização da plataforma para apresentação de vídeo-gravação do experimento, assim apresentado como reposta. Verificamos, também, que há o uso de kits disponibilizados pela instituição quando há os encontros nos polos para o desenvolvimento das aulas. Enfim, não diferenciando muito do que se apresenta no PPC do curso.

As disciplinas experimentais (mecânica, termodinâmica, eletricidade, magnetismo etc.), na modalidade a distância, são atividades presenciais, realizadas nos polos de apoio presencial em que o professor leva um kit da universidade, que pode ser um material alternativo ou mais elaborado e realiza as atividades, organizadas em um roteiro, junto com os licenciandos e apoiado por um tutor. A metodologia consiste em uma explicação da atividade, utilizando o quadro, projeção e um roteiro. Dependendo do tamanho da turma, as atividades são realizadas em duplas ou ainda formando grupos com mais licenciandos. Os licenciandos respondem às questões do roteiro e, em momento posterior, deverão entregar um relatório da(s) atividade(s) experimental(is).

No que concerne ao estímulo de se utilizarem os meios tecnológicos, podemos observar que os docentes têm liberdade de utilizar simulações para exemplificar um fenômeno. Mas as atividades experimentais são basicamente em forma de montagem de um experimento (com materiais alternativos ou kits já prontos), seguidas de um roteiro para a elaboração do relatório, assim evidenciado não somente no PPC como também nas respostas que recebemos.

Quadro 21 - Resposta do coordenador da instituição L11

Em relação às disciplinas de laboratório, são utilizadas a estrutura do Departamento de Física para as aulas de Laboratório do curso de Física a distância. Sendo ministradas no mesmo laboratório a que os licenciandos do curso presencial têm acesso. Então, não há nenhuma especificidade.

(Fonte - Organizado pelos autores)

Nas respostas apresentadas, nota-se que não há diferença de um curso presencial para o curso a distância que a instituição oferece, em relação à 
metodologia adotada, bem como na utilização do laboratório para execução das disciplinas experimentais. Fica evidenciado que todas ocorrem presencialmente. Ao comparar com o que se apresenta no PPC, observa-se que as aulas que requerem atividade em laboratório são executadas presencialmente no polo. Sendo acompanhada pelo tutor e/ou supervisor, assim chamado, porém, possibilitando um complemento com videoconferência e a utilização da plataforma para apresentação de vídeos ou orientações.

Observamos no PPC que há o estímulo de desenvolver a utilização de simulações, como é pontuado em uma das ementas, nas simulações computacionais sobre mecânica de uma partícula, de um sistema de partículas e do corpo rígido e sobre termodinâmica básica. Mas, ao comparar com a reposta apresentada, não conseguimos confirmar essa possibilidade e nem outras que são pontuadas no PPC.

Quadro 2J - Resposta do coordenador da instituição M12

\begin{abstract}
a) As disciplinas Física Experimental I, II, III, IV e Laboratório de Física Moderna (30 horas cada) e Laboratório de Eletrônica (60 horas) são idênticas, em conteúdos e carga horária, às do ensino presencial.

b) As aulas experimentais são ministradas nos polos de apoio presencial.

c) Em cada polo existe apenas uma sala com quatro bancadas, onde são guardados todos os equipamentos do laboratório de ensino.

d) Os equipamentos dos laboratórios foram comprados pela Secretaria de Educação do Estado, aliás a maioria dos polos do nosso estado são estaduais, adquiridos em 2007 e 2008. Por isso mesmo, os equipamentos têm pouca qualidade e são em pequenas quantidades. Para a realização das aulas práticas é feito normalmente um rodízio de experimentos entre os grupos devido à quantidade limitada de equipamentos. A ausência de determinados equipamentos é suprimida com a confecção de materiais alternativos e/ou equipamentos dos laboratórios dos cursos presenciais que são levados aos polos.

e) Normalmente, as aulas experimentais são realizadas simultaneamente em todos os polos e os professores das disciplinas experimentais são os mesmos que atuam no ensino presencial os quais treinam os tutores a distância que vão aos polos onde eles não vão ou não podem ir.

f) São realizados dois encontros presenciais em média para cada disciplina experimental, com duração de 8 horas cada um.

g) Para a realização das aulas, os licenciandos são divididos em grupos e depois fazem um relatório por grupo. A nota final de cada avaliação é 10 pontos, sendo definida pela nota do relatório (presencial) mais uma parte não presencial composta por fóruns e tarefas teóricas sobre os conteúdos abordados nos experimentos.
\end{abstract}

(Fonte - Organizado pelos autores)

Esta instituição apresentou pontualmente a forma que ocorre metodologicamente o curso, como, especificamente, disciplinas experimentais. Algumas disciplinas têm características de disciplinas presenciais. Diferenciando, nesse caso, que as aulas são ministradas nos polos com o acompanhamento do tutor. Percebe-se que os polos têm estrutura para a execução das atividades com equipamentos e preparo para o recebimento dos licenciandos.

Foi pontuado que os equipamentos foram adquiridos pela secretaria do estado, pois os polos pertencem ao estado, evidenciando-se aqui uma parceria entre instituição de ensino superior e governo do estado. Quando não há equipamentos suficientes e necessários, é suprida com a confecção de materiais 
alternativos e/ou equipamentos dos laboratórios dos cursos presenciais que são levados aos polos. Essas informações não estão claras no PPC, nem mesmo se há uma parceria para o funcionamento do curso. Outro ponto relevante percebido aqui é que não há muitos encontros nos polos.

\section{CONSIDERAÇÕES}

Podemos destacar o resultado que decorreu ao analisar os PPC, conjuntamente com os currículos e ementas. Essa iniciativa oportunizou-nos conhecer mais claramente os diversos PPC com suas especificações, desde a apresentação, o desenvolvimento histórico do curso, bem como os pontos que foram levantados com este trabalho.

Ao estabelecer as ações, centramo-nos no objetivo de verificar o que existe na prática de conteúdo sobre Física experimental desenvolvida em laboratório, de forma presencial e a distância, em cursos de licenciatura em Física a distância no Brasil. Determinamos, para a primeira pergunta, a consideração de que a concentração das disciplinas que são trabalhadas se evidenciam nas Físicas experimentais I, II, III e IV. Entretanto, a Física experimental IV não foi evidenciada por todas. Desse modo, podemos observar, em termos gerais, que a maioria delas trabalha pelos menos as três Físicas no curso.

Para a segunda pergunta, fica esclarecido que as metodologias são diversas, desde a interpretação do experimento com uma atividade real até a construção de um relatório. Das dez instituições, quatro delas tentam utilizar vídeos, webconferência, simulação e/ou exploração do desenvolvimento de habilidades na construção um experimento. Nessa parte de explicar como são ministradas as aulas experimentais, em nove instituições, as aulas são desenvolvidas presencialmente no laboratório didático real, considerando que seja no polo ou na sede da instituição. Somente uma instituição explicou que a atividade é realizada a distância, com kits de experimentos que o licenciando recebe em sua casa, acompanhada de um roteiro de explicações.

Em vista desses aspectos, observa-se que a utilização da tecnologia na aprendizagem é um instrumento eficaz para desenvolver o trabalho cooperativo, o aprender a aprender, a habilidade de tomar decisões, de processar e criar conhecimento, principalmente porque esse pensamento foi verificado nos argumentos gerais que verificamos nos PPC.

Pontuamos a terceira pergunta com o objetivo de verificar se iria surgir algo novo nessa ideia, ou até mesmo de identificar quais as instituições que estão desenvolvendo meios para os futuros professores de Física que estarão entrando para essa geração de visões tecnológicas evoluídas ou criativas. Todavia, não tivemos muitas novidades nesse ponto, porquanto evidenciamos poucas manifestações ou preocupações em relação a esse pensamento.

Poderíamos destacar várias significações para definir a tecnologia e seu alto poder de motivação e estímulo para o desenvolvimento da criatividade. $\mathrm{O}$ que consideramos para a terceira pergunta são as poucas atividades que possibilitam esse estímulo nos licenciandos. O aluno sempre deve ser considerado o protagonista da aprendizagem, contudo não percebemos o estímulo para o licenciando criar. O máximo que eles desenvolvem nas atividades é o acompanhamento dos roteiros, criação dos relatórios, observação das aulas que 
são expostas em vídeos, e explicações a partir da realização dos experimentos. De igual forma, não percebemos a utilização de software para desenvolver uma atividade experimental ou até mesmo para confirmar uma atividade experimental que foi realizada no laboratório didático real. Enfim, não observamos nos PPC, e nem nas explicações obtidas, a utilização de um laboratório virtual.

Tratando da formação de futuros professores de Física, que são hoje licenciandos inseridos nos cursos que disponibilizam toda uma argumentação de que utilizam e fomentam o uso de tecnologias, a partir da verificação, não conseguimos observar esse ponto, ao comparar os PPC com as argumentações que nos foram apresentadas.

Fazendo um levantamento das leis que amparam esses cursos, das referências que dão um olhar direcionando para uma caminhada de evoluções, conseguimos verificar que as atividades experimentais são desenvolvidas da mesma forma como se fosse em um curso presencial. Conforme evidenciado nos argumentos dos coordenadores, as plataformas são até utilizadas, mas para uma comunicação e/ou para apresentação de dúvidas e entrega de material e trabalhos, tão somente. Não fica muito claro o uso dessas plataformas para a exploração de experimentos virtuais. 


\title{
An analysis of the content developed versus curricular content in physics courses distance: a meticulous look at the experimental subjects
}

\begin{abstract}
This work has the objective of verifying what exists in the practice of content on experimental Physics developed in the laboratory, face and distance, in undergraduate courses in distance Physics in Brazil. We used a content analysis of eleven curricula and their respective syllabuses, complemented with information from ten course coordinators. We created some categories based on the experimental contents studied in the course. In addition, we determine the methodology applied by teachers in these experimental disciplines. Based on the results obtained, we observed that most of the teachers develop their subjects in a similar way to the ones taught to the licenciandos, but not discarding, when possible, the use of the virtual platform to complement the encounters when they occur in the experimental didactic laboratory in the classroom. According to the guidelines we find, we consider that the courses try to use the requirements according to the laws, with a diversity of methodologies, which we present in this work.
\end{abstract}

KEYWORDS: Experimental physics. Distance education. Technology. 


\section{NOTAS}

1 PPC - Projeto Pedagógico Curricular desenvolvido por cada instituição, tem características diferenciadas, conforme a cultura e região.

\section{REFERÊNCIAS}

BARDIN, L. Análise de conteúdo. Lisboa: Edições 70 Ltda., 2011.

BRASIL. Parecer CNE/CES no 1304, de 6 de novembro de 2001. Diretrizes Nacionais para os cursos de Física. Disponível em: $<$ http://portal.mec.gov.br/cne/arquivos/pdf/CES1304.pdf>. Acesso em: 20 de maio de 2016.

. Resolução CNE/CES no 9, de 11 de março de 2002

Diretrizes Curriculares para os cursos de Bacharelado e Licenciatura em Física. Disponível em: <http://portal.mec.gov.br/cne/arquivos/pdf/CES09-2002.pdf>. Acesso em: 15 de maio de 2016.

Lei de Diretrizes e Bases da Educação Nacional, no 9394, de 20 de dezembro de 1996. Disponível em: $<$ http://portal.mec.gov.br/arquivos/pdf/ldb.pdf $>$. Acesso em: 15 de maio de 2016.

. Ministério da Educação / SESU / Grupo Tarefa: Subsídios para a elaboração de Diretrizes Curriculares para os Cursos de Formação de Professores. Brasília, setembro de 1999. Disponível em: <http://portal.mec.gov.br/cne/arquivos/pdf/009.pdf>. Acesso em: 15 de maio de 2016.

. Ministério da Educação - Proposta de Diretrizes para a Formação de Professores da Educação Básica em Nível Superior. Brasília, maio de 2000. Disponível em: <http://portal.mec.gov.br/cne/arquivos/pdf/009.pdf>. Acesso em: 17 de maio de 2016.

. Conselho Nacional de Educação. Resolução CEB n. 03/98. Brasília, 26 de junho de 1998. Disponível em:

<http://portal.mec.gov.br/cne/arquivos/pdf/009.pdf>. Acesso em: 17 de maio de 2016.

. Conselho Nacional de Educação. Parecer CEB n. 15/98. Diretrizes 
26 de junho de 1998. Disponível em:

<http://portal.mec.gov.br/cne/arquivos/pdf/009.pdf>. Acesso em: 17 de maio de 2016.

CAVALCANTE, R. B.; CALIXTO, P.; PINHEIRO, M. M. K. Análise de Conteúdo: considerações gerais, relações com a pergunta de pesquisa, possibilidades e limitações do método. Revista Inf. \& Soc. v.24, n.1, p. 13-18, 2014.

GUTERRES, D. H. S.; VELOSO, M. S. S. de O.; ALMEIDA, I. J. G.; ARAÚJO, I. G. A UTILIZAÇÃO DE PLATAFORMAS DIDÁTICAS VIRTUAIS NO ENSINO DE FÍSICA. CIET:EnPED, [S.I.], maio 2018. ISSN 2316-8722. Disponível em: <http://cietenped.ufscar.br/submissao/index.php/2018/article/view/258>. Acesso em: 07 set. 2018.

LLOYD, C. Inovação e Qualidade na Educação a Distância na Universidade Aberta, RU. In: Inovação e Qualidade na Universidade. AUDY, J. L. N.; MOROSINI, M. C. Porto Alegre: EDIPUCRS, 2008. 520p.

NETTO, C.; GIRAFFA, L. M. M. Licenciaturas na Modalidade a Distância e o Desafio da Qualidade: uma proposta de indicadores para aferir qualidade nos cursos de Física, Química, Biologia e Matemática. Renote, v.7 n.3, 2009.

PARA, R. D. Q. Ministério da Educação Secretaria de Educação a Distância, 2007. Disponível em:

<http://portal.mec.gov.br/seed/arquivos/pdf/legislacao/refead1.pdf>. Acesso em: 10 de fevereiro de 2015.

RODRIGUES, C. M. C.; NUNES, R. S.; BEUREN, G. M.; MIORANDO, B. S. Avaliação de Cursos de Graduação na Modalidade a Distância: uma Experiência no Curso de Graduação em Administração da Universidade Federal de Santa Catarina. Revista GUAL. Florianópolis, v. 7, n. 1, p. 191-212, jan. 2014.

SILVA, A. C. Aprendizagem em Ambientes Virtuais e Educação a Distância. Editora Mediação, Porto Alegre, 2009.

SOUZA, C. S. B. N. D. Licenciaturas na Modalidade a Distância e o Desafio da Qualidade: uma proposta de indicadores para aferir qualidade nos cursos de física, química, biologia e matemática. Pontifícia Universidade Católica do rio Grande do Sul. Porto Alegre, p. 186. 2009. 
ensino de física a distância. Revista Tecnologias na Educação, ano 8 n/v. 17, 2016.

Recebido: 2016-11-04

Aprovado: 2018-11-09

DOI: $10.3895 /$ rbect.v11n3.4989

Como citar: VELOSO, M. S. O.; SERRANO, A. Um olhar meticuloso das disciplinas experimentais dos cursos de física à distância. Revista Brasileira de Ensino de Ciência e Tecnologia, v. 11, n. 3, 2018. Disponível em:

<https://periodicos.utfpr.edu.br/rbect/article/view/4989>. Acesso em: xxx.

Correspondência: Maria Sônia Oliveira Veloso - soniaufrr@gmail.com

Direito autoral: Este artigo está licenciado sob os termos da Licença Creative Commons-Atribuição 4.0 Internacional. 